\title{
EDUCAÇÃO CORPORATIVA NA PERSPECTIVA DA INTELIGÊNCIA ORGANIZACIONAL
}

\author{
EDUCAÇÃO CORPORATIVA NA PERSPECTIVA DA \\ INTELIGÊNCIA ORGANIZACIONAL
}

\author{
Kelly Cristina Wilhelm de Toni * \\ Lillian Maria Araújo de Rezende Alvares**
}

\begin{abstract}
RESUMO:
Introdução: Para enfrentar os desafios da competitividade e alcançar as condições para geração de inovação é preciso assegurar-se que a força de trabalho se mantenha altamente qualificada. Nesse contexto, a educação corporativa surge como uma alternativa.

Objetivo: Propor um método para analisar a relação entre as abordagens de processo da Inteligência Organizacional e Educação Corporativa.

Metodologia: Construção teórica realizada com base na revisão de literatura. E construção de uma abordagem metodológica ligada ao problema desta pesquisa.

Resultados: Identificação de um conjunto de elementos comuns entre as abordagens: a "Captura" e "Compartilhamento" de conhecimentos e experiências, o "Significado" compartilhado e a "Cultura" de aprendizado individual e organizacional.

Conclusões: Existe uma verdadeira conexão entre as abordagens do estudo. $O$ método proposto pode ser percebido como um instrumento para explicar e avaliar o processo de educação nas corporações pela perspectiva da inteligência organizacional.
\end{abstract}

Palavras-chave: Educação Corporativa. Inteligência Organizacional. Educação Corporativa e Inteligência Organizacional.

\section{INTRODUÇÃO}

O padrão socioeconômico, político e cultural da sociedade contemporânea estabelece que a sobrevivência das organizações na época da competitividade e inovação depende agora da sua capacidade em obter

*Mestra em Ciência da Informação pela Universidade de Brasília (UnB). E-mail: kellydetoni@gmail.com

**Doutora em Ciência da Informação pela Universidade de Brasília e pela Université du Sud Toulon-Var (Doctorat de Sciences de I'Information et de la Communication) em regime de cotutela. Coordenadora-Geral de Produtos Consolidados do Instituto Brasileiro de Informação em Ciência e Tecnologia (IBICT). E-mail: lillianalvares@unb.br 
informação, novos conhecimentos, aprender rapidamente e incorporar novas competências às práticas do negócio.

Para tanto, é imperativo intensificar a inteligência da organização ajustando e aperfeiçoando sistemas e processos, não apenas para gerenciar informação e conhecimento em si, mas para capacitar a empresa em usar esses recursos de forma efetiva na definição de estratégias e na identificação e disseminação de boas práticas na consecução de seus objetivos e missão.

A partir dessa percepção, para que uma empresa possa acompanhar a dinâmica do ambiente em que está inserida e perceber as necessidades de melhorias em suas estruturas para atuar sempre com efetividade, é preciso que tenha uma força de trabalho altamente qualificada que represente a inteligência organizacional.

Essas qualificações estão diretamente ligadas ao conhecimento, as habilidades e as competências profissionais essenciais para que o trabalhador se adapte às novas tecnologias e mudanças que afetam o ambiente de trabalho. Assim, as demandas por educação e aprendizado contínuo adquirem muita importância, porque aumentam as chances de uma organização responder de forma adequada, e com sucesso, a um mundo em constante transformação.

Nesse contexto, e considerando as premissas estabelecidas, a educação corporativa surge como uma alternativa para suprir as organizações dos instrumentos necessários ao alcance desses propósitos, isto é, para desenvolver e aprimorar a inteligência individual e organizacional (MEISTER, 1999; TERRA, 2000; EBOLI, 2004; TARAPANOFF, 2004, 2006; ALLEN, 2002, 2007).

Por essas e outras razões, esse fenômeno recebe cada vez mais atenção no meio corporativo, e vem crescendo de forma expressiva em muitos países, inclusive no Brasil. As universidades corporativas em 1999 eram apenas dez em todo o país (EBOLI, 1999). Passada uma década, em 2009, o número de empresas que investiram nesse modelo de capacitação e aprimoramento de funcionários cresceu $2.400 \%$, atingindo duzentas e cinquenta unidades (EBOLI, 2009). 
Atualmente, se estima que o número de universidades corporativas no Brasil tenha dobrado desde 2009, ou seja, exista cerca de quinhentas empresas, entre nacionais e multinacionais, que adotam o conceito e princípios de educação corporativa. O número foi projetado ao longo das edições da Pesquisa Nacional - Práticas e Resultados da Educação Corporativa de 2009 a 2012 (FIA, 2012). Essas empresas entenderam que quanto mais pessoas qualificadas tiverem em seus quadros, mais inteligentes e competitivas serão.

Sob esses argumentos, se considera relevante conhecer a contribuição e o potencial da educação corporativa, num cenário em que a inteligência organizacional, constituída em essência pelo capital de conhecimento e competências profissionais, representa um dos grandes indutores da competitividade, da inovação e da sustentabilidade empresarial.

Nesse patamar, discute-se sobre a seguinte problemática: Como abordar a relação existente entre a Inteligência Organizacional e a Educação Corporativa?

Este artigo, portanto, tem por objetivo apresentar o resultado de uma pesquisa que está fundamentada sobre um referencial teórico que permitiu propor um método para analisar a relação entre as abordagens de Inteligência Organizacional e Educação Corporativa.

O problema tratado na Ciência da Informação se refere ao uso da informação na construção de significados (CHOO, 2003) ou de inteligência nas organizações, tal como é estudado em linhas de pesquisas das áreas de Gestão da informação e do conhecimento, e de Inteligência organizacional e competitiva.

\section{METODOLOGIA}

A metodologia de pesquisa utilizada para o desenvolvimento deste trabalho permite classificá-la quanto aos seus objetivos como sendo descritiva, e quanto aos procedimentos como bibliográfica.

Os objetivos deste estudo foram alcançados por meio da convergência de duas linhas de ação. A primeira diz respeito à construção teórica realizada com base na revisão de literatura e na reflexão das autoras. A segunda à 
construção de uma abordagem metodológica diretamente ligada ao problema desta pesquisa.

Para chegar a esse intento, em síntese, cada objetivo específico do estudo necessitou de métodos e técnicas adequadas, como descrito no quadro 1.

Quadro 1 - Objetivos, métodos e fontes.

\begin{tabular}{|c|c|c|}
\hline Objetivos específicos & $\begin{array}{l}\text { Métodos de } \\
\text { investigação }\end{array}$ & Fontes de coleta dos dados \\
\hline $\begin{array}{l}\text { Identificar um referencial } \\
\text { teórico para inteligência } \\
\text { organizacional } \\
\text { educação corporativa. }\end{array}$ & \multirow{2}{*}{ Pesquisa Bibliográfica } & $\begin{array}{l}\text { Revisão de literatura. } \\
\text { (Livros, revistas, artigos } \\
\text { científicos, teses, dissertações. } \\
\text { Bases de dados }{ }^{1} \text { nacionais e } \\
\text { estrangeiras; internet }{ }^{2} \text {.) }\end{array}$ \\
\hline 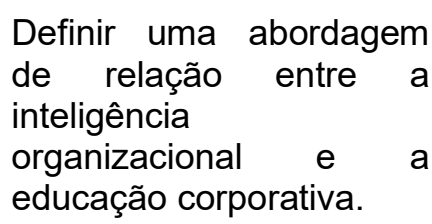 & & Referencial teórico proposto. \\
\hline
\end{tabular}

Fonte: Das autoras (2015)

\section{REFERENCIAL TEÓRICO}

\subsection{Gestão do Conhecimento}

Em grande maioria, as definições encontradas na literatura sobre a gestão do conhecimento estão ligadas ao conceito de processo e ressaltam o contexto das organizações, o vínculo estreito com as estratégias de negócio, as competências e o conhecimento organizacional.

O conhecimento é a informação interpretada, isto é, o que cada informação significa e que impactos no meio cada informação pode causar, de modo que ela possa ser utilizada para importantes ações e tomadas de decisões (DUMONT et al, 2006, p. 286).

1 Banco de teses da Capes (http://bancodeteses.capes.gov.br); Biblioteca Digital de Teses e Dissertações do Instituto Brasileiro de Informação em Ciência e Tecnologia - IBICT (http://bdtd.ibict.br/); Biblioteca Digital de Teses e Dissertações da Universidade de Brasília UNB (http://bdtd.bce.unb.br); Biblioteca Digital de Teses e Dissertações da Universidade Católica de Brasília - UCB (http://www.bdtd.ucb.br).

2 Mecanismos de busca Google (https://www.google.com.br); Acadêmico (https://scholar.google.com.br). 
A ideia principal está em torno de elementos para facilitar a captura de informações e conhecimentos da organização como um todo, e colocá-los à disposição das pessoas, como subsídio à realização dos objetivos organizacionais. Pois, gerenciar o conhecimento é oferecer condições que permitam que o conhecimento seja criado, adquirido, compartilhado e utilizado na consecução das estratégias de negócio de uma organização (TERRA, 2000; SVEIBY, 2001a; STOLLENWERK, 2001; WOIDA; VALENTIM, 2004).

Dessa forma, os desafios a serem superados quanto à gestão do conhecimento são: (i) conectar eficientemente aqueles que sabem com aqueles que necessitam saber; e (ii) converter conhecimento pessoal em conhecimento da organização.

A construção dos conceitos e práticas de gestão do conhecimento seguem, portanto, duas grandes tendências de acordo com Sveiby (2001a). A primeira, voltada para a gestão da informação com ênfase nas tecnologias de informação. A segunda, voltada para a gestão de pessoas com foco na aprendizagem organizacional.

Assim, existe uma concordância entre os autores citados, que a gestão do conhecimento geralmente possui as seguintes intenções: (i) adaptar a organização ao uso intensivo do conhecimento; (ii) tornar o conhecimento disponível e descrever como é aplicado na organização; (iii) desenvolver uma cultura que estimule o compartilhamento de conhecimentos, e a ação de procura e reutilização do conhecimento; e (iv) construir a infraestrutura do conhecimento, não apenas com sistemas e tecnologias, mas na formação de uma rede de conexões entre as pessoas, motivando e oferecendo à elas um conjunto de condições e ferramentas para que possam colaborar e trocar experiências e informações, criar novos conhecimentos e competências, e então, inovar.

\subsubsection{Conhecimento Organizacional}

Considerados autores clássicos na literatura sobre gestão do conhecimento, Nonaka e Takeuchi (1997) se detiveram ao processo de criação do conhecimento na organização. O conceito central se apoia na interação 
contínua e dinâmica entre a conversão do conhecimento tácito em conhecimento explícito, e entre o indivíduo e a organização.

O conhecimento tácito é aquele que reside apenas na cabeça das pessoas, que é difícil de expressar, porque não está descrito ou documentado em lugar nenhum, dificultando sua comunicação e compartilhamento. Está profundamente ligado à experiência e à ação do indivíduo, assim como as ideias e intuições.

O conhecimento explícito é aquele que está registrado ou codificado de alguma forma, assim disponível para as demais pessoas materializado em livros, manuais, documentos, imagens, sons, etc., e podendo ser processado por computador, transmitido eletronicamente ou armazenado em banco de dados e repositórios.

Para que os aspectos subjetivos do conhecimento tácito sejam compartilhados na organização, é necessário convertê-los em formatos compreensíveis a todos, ou seja, convertê-lo em conhecimento explícito.

Nonaka e Takeuchi (1997, p. 80) explicam que a criação do conhecimento inicia com a socialização e passa através de quatro modos de conversão do conhecimento que podem ser descritos como a seguir:

(i) Tácito para tácito (socialização) - troca de experiências e modelos mentais ou habilidades técnicas compartilhadas, ou seja, criação do conhecimento tácito.

(ii) Tácito para explícito (externalização) - articulação do conhecimento tácito em explícito, ou seja, criação do conhecimento novo expresso e codificado na forma de analogias, conceitos, hipóteses ou modelos.

(iii) Explícito para explícito (combinação) - combinação de conjuntos diferentes, novos e antigos, de conhecimento explícito.

(iv) Explícito para tácito (internalização) - incorporação do conhecimento explícito no conhecimento tácito.

A criação do novo conhecimento se resume à conversão do conhecimento tácito em conhecimento explícito. De forma sintética, para construir o conhecimento organizacional o indivíduo precisa exteriorizar seu conhecimento. Pelos modos de conversão, o conhecimento individual pode ser disponibilizado para o aprendizado do grupo e disseminado para todos os níveis organizacionais, e então incorporá-lo à produtos, serviços e sistemas. 
Além dos conhecimentos tácito e explícito, Choo (1998) distingue ainda o cultural. Este conhecimento consiste das estruturas afetiva e cognitiva qual inclui suposições, valores e crenças da organização que doam significado à informação.

Como o conhecimento é criado essencialmente por indivíduos, o que deve ser feito em gestão do conhecimento é desenvolver as competências individuais como base às competências organizacionais. Pois, ocorre que transformar informações não estruturadas em conhecimento aplicado à inovação de serviços e produtos, é um processo que está altamente relacionado às habilidades pessoais.

\subsubsection{Competência Organizacional}

O tema competência se insere entre os conceitos propostos para orientar o processo de gestão do conhecimento, à medida que se propõe alinhar o aperfeiçoamento profissional dos indivíduos à estratégia e aos objetivos organizacionais.

O conceito de competência organizacional, de acordo com Fleury e Fleury (2004, p. 46), seria a capacidade da organização de combinar, misturar e integrar recursos em produtos e serviços.

Tal noção é representada pela "combinação sinérgica de conhecimentos, habilidades e atitudes expressas pelo desempenho profissional dentro de um determinado contexto organizacional" (CARBONE et al., 2005, p. 76).

Nessa perspectiva, as competências organizacionais são as competências necessárias para que a empresa e os indivíduos no trabalho realizem os objetivos organizacionais. Porém, para agregar valor, as competências individuais devem ser consideradas no seu alinhamento com as competências essenciais ${ }^{3}$ da organização.

Ao definir sua estratégia competitiva, a organização identifica as competências essenciais do negócio e as competências adequadas a cada função - as competências organizacionais. Identificando quais são as

${ }^{3}$ Competências essenciais são aquelas que diferenciam e que garantem uma vantagem competitiva à organização perante as demais (FLEURY; FLEURY, 2004, p. 47).

Inf. Inf., Londrina, v. 21, n. 3, p. 228 - 257, set./dez., 2016. 
competências essenciais para o sucesso da organização, essas devem ser desdobradas em termos de competências profissionais e desenvolvidas junto à sua força de trabalho.

No contexto organizacional, as competências estão sempre em construção dando espaço ao aprender. Pois, de acordo com Zarifian (2003, p. 137) os conhecimentos adquiridos se transformam conforme aumenta a complexidade das situações de trabalho onde a competência é solicitada. Assim, autores como Fleury; Fleury (2004), Zarifian (2003), Carbone et al. (2005) e Brandão (2011), inferem que as competências estão estreitamente relacionadas à aprendizagem.

Portanto, para desenvolver competências e novos conhecimentos em uma organização é preciso percorrer o caminho que vai da aprendizagem individual, para a aprendizagem em grupo, e para aprendizagem organizacional.

As estratégias, então, definem as competências que redefinem as estratégias pela aprendizagem. Com efeito, esse processo gera um "círculo ininterrupto" de escolhas estratégicas e de competências, em que uma é dependente da outra.

\subsubsection{Aprendizagem organizacional}

A aprendizagem organizacional é o elemento articulador e facilitador da criação do conhecimento e desenvolvimento de competências organizacionais. Pois, se trata do processo dinâmico e contínuo que ocorre nos níveis de indivíduos, grupos e organização, pelo qual oportuniza a aquisição e transferência de conhecimentos.

A aprendizagem individual é a base para a compreensão do processo de aprendizagem organizacional. Porém, embora as organizações aprendam a partir da experiência e da ação dos seus indivíduos, o aprendizado organizacional não se reduz ao aprendizado individual. Para Antonello (2005, p. 18), ela ocorre na medida em que todos os integrantes experimentam uma situação problemática e a investigam empregando um olhar organizacional, respondendo a este fato com um modo de pensar e agir que modifica seus 
modelos mentais e reestrutura suas atividades de forma a alcançar os resultados previamente esperados.

Seguindo este raciocínio, os indivíduos então aprendem quando estão envolvidos em atividades que exigem interação com os outros e com o meio exterior. Dessa forma, a aprendizagem é relevante quando compartilhada em nível coletivo, assim, destacando a importância do grupo nesse processo.

As percepções capturadas por uma visão compartilhada, dificilmente podem ser imaginadas por um indivíduo. Senge (2004, p.19) defende que a aprendizagem em grupo é vital, pois as equipes, e não os indivíduos, são a unidade fundamental de aprendizagem e de trabalho nas organizações modernas.

Na organização, a aprendizagem busca desenvolver a capacidade de aprender continuamente com as experiências e conhecimentos de seus membros e transformar esses conhecimentos em comportamentos que contribuam para um melhor desempenho organizacional. As organizações que aprendem refletem sobre suas experiências passadas, filtram-nas em lições úteis, compartilham o conhecimento internamente e asseguram-se de que os erros não sejam repetidos em outras atividades/situações (GARVIN, 2001, p. 15).

Resumidamente, o processo ocorre com a transferência de conhecimentos na organização, isto é, quando as ações do indivíduo fluem para o grupo e para a organização. Por sua vez, o que já foi aprendido e incorporado pela organização, retroalimenta o aprendizado individual afetando a forma como as pessoas pensam e agem. A aprendizagem, assim, é conduzida pelo uso do conhecimento organizacional.

\subsection{Inteligência Organizacional}

Parte da discussão sobre inteligência organizacional está voltada à habilidade da organização em mobilizar recursos e capacidades para transformar informação em conhecimento, e utilizar este conhecimento no auxílio à tomada de decisão e resolução de problemas, e por sua vez, na manutenção e melhoria da sua performance em um ambiente competitivo. 
$\mathrm{Na}$ hierarquia da informação, a inteligência é a informação com oportunidade, isto é, o conhecimento contextualmente relevante, sintetizado e aplicado a uma determinada situação (MORESI, 2001, p. 118).

Uma organização inteligente busca alcançar seus objetivos em um ambiente externo em constante mudança, adaptando seu comportamento de acordo com o conhecimento sobre seus cenários interno e externo.

No meio externo, a organização prospera navegando entre ameaças e oportunidades (concorrentes, clientes, fornecedores). E no interno, indivíduos e grupos (membros da organização) atualizam e ampliam seus conhecimentos e competências, possibilitando a organização agir e aprender.

Sob a perspectiva dos trabalhos de Choo (1998; 2003), a organização inteligente faz isso por meio da gestão e criação do conhecimento organizacional, oferecendo as condições necessárias ao crescimento sustentável no ambiente dinâmico e competitivo das empresas. Primeiro, a empresa interpreta a informação sobre o ambiente, dando significado ao que acontece à organização e ao que ela faz. Depois, cria novos conhecimentos compartilhando e combinando a experiência de seus membros para aprender e inovar. E por fim, processa e analisa a informação escolhendo e empreendendo formas racionais de ação. O objetivo principal é integrar tais atividades num ciclo contínuoque revigore a organização por meio de informação e conhecimento capazes de levá-la a agir de maneira inteligente.

Nesse ponto de vista, a inteligência de uma organização, de acordo com Tarapanoff (2001, p. 314) é a sua habilidade em adquirir informações e conhecimentos, se adaptar ao meio, fazer julgamentos e desenvolver estratégias para agir de modo racional com base nas informações obtidas.

A referida inteligência, então, está associada a uma cultura organizacional que tem como base o domínio do conhecimento - criar, gerenciar, compartilhar e distribuir - e é pautada por meio de eficientes sistemas de informação para aplicá-lo estrategicamente em seus ambientes de trabalho, com foco nos negócios da empresa.

Para representar essa inteligência organizacional é preciso que se tenha uma força de trabalho altamente qualificada. Isso significa, saber perceber mudanças no ambiente, capturar informações, aumentar o nível de 
aprendizado, desenvolver competências, criar novos conhecimentos e agir com base nestes, comportando-se de forma adaptativa para alcançar os objetivos e missão organizacionais.

A inteligência organizacional pode ser vista sob duas perspectivas mutuamente dependentes: como processo (criação) e como produto (resultado).

Segundo Matsuda (1993), a inteligência organizacional como processo, refere-se à coordenação e integração de atividades que envolvam a interação entre inteligências humana e tecnológica, com o objetivo de agregar inteligência à organização como um todo. Enquanto produto, refere-se ao resultado do processo de inteligência como um sistema de informação estruturado, sintetizado e direcionado para um objetivo, que é potencializar a capacidade de solução de problemas e tomada de decisões.

Enquanto processo, objeto deste estudo, os principais modelos de inteligência organizacional encontrados na literatura pesquisada remetem aos trabalhos de Matsuda (1993) e Choo (1998), os quais propõem atividades e componentes, que inter-relacionados, podem criar as condições necessárias para que a organização possa gerar conhecimento, inovar e adaptar-se à dinâmica e complexidade do ambiente, possibilitando o alcance dos objetivos organizacionais, a realização da missão e a conquista da vantagem competitiva.

\subsubsection{Abordagem de Inteligência Organizacional segundo Matsuda (1993)}

O processo de inteligência organizacional na visão de Matsuda (1993) inclui cinco subprocessos que envolvem pessoas e tecnologias, que de forma conjunta e inter-relacionada num fluxo de interação podem contribuir para o alcance de vantagens competitivas por meio da inteligência individual e coletiva da organização. Esses subprocessos são: a cognição, a memória, a comunicação, o raciocínio e o aprendizado.

A cognição organizacional se refere à percepção ou leitura das imagens dos ambientes interno e externo da organização. Logo, as atividades ligadas a coleta de informações e mediadas por tecnologias estão envolvidas nesse processo. Em muitos casos, a leitura das imagens é feita com base em 
experiências ou memórias passadas da organização que podem ser utilizadas para criar novos significados e ações efetivas para a melhoria do desempenho. Desenvolvido pela organização, a cognição é um processo de identificação de padrões, captação de dados, processamento e organização de informações em bancos de dados de memória, realizando análise, diagnóstico e produzindo conhecimento sobre o ambiente com o propósito de apoiar a resolução de problemas e a tomada de decisão.

A memória organizacional se refere ao armazenamento e recuperação de conhecimentos e experiências vivenciadas pela organização, para que possam ser utilizadas no futuro com a finalidade de aprendizado e subsidiar ações e decisões. Esse processo compreende (i) memórias dos indivíduos, por meio do registro de experiências dos membros da organização; (ii) de tecnologias, por meio da construção de bases de dados e de conhecimentos; (iii) da memória institucional, por meio da manutenção de documentos e arquivos importantes, relatórios sobre atividades, manuais de procedimento, padronização de tarefas, métodos e técnicas específicas, dentre outros; e (iv) da memória cultural, por meio da própria cultura da organização, tradições, crenças compartilhadas, linguagens próprias e outros recursos utilizados pelos membros.

O subprocesso de comunicação organizacional se refere à troca de dados, informações e conhecimentos da organização como um todo. Contempla, assim, as inteligências individuais, de grupo e da organização. Busca desenvolver formas de acesso a informação dentro de um ambiente organizacional aberto, e favorecer a interação entre seus membros internos, e entre a organização e seu ambiente externo, para promover a disseminação e criação de novos conhecimentos. E que por sua vez, pode ser facilitado e maximizado quando mediado por tecnologias de informação e comunicação (TIC). Em síntese, é a forma de transferência de informações e conhecimentos que flui entre indivíduos e tecnologias em uma organização, além daquele que ocorre entre uma organização e seu ambiente.

Já o raciocínio organizacional se refere a condição que a organização adquire de prever e resolver situações e problemas organizacionais, utilizando as informações disponíveis juntamente com os recursos e competências 
presentes no seu ambiente para a melhor tomada de decisão de acordo com a situação que se apresenta. Dentro de um pensamento sistêmico e estratégico, o raciocínio é o processo de decidir a partir dos objetivos, das suas alterações e dos recursos utilizados para alcançá-los, as diretrizes ou políticas que irão nortear a aquisição, o uso e distribuição desses mesmos recursos. Esse elemento mostra até que ponto a empresa e suas formas de operar expressam a visão estratégica e as prioridades essenciais ou críticas para o sucesso.

Por fim, o aprendizado organizacional se refere à capacidade da organização em modificar o seu comportamento com base nos conhecimentos resultantes das suas experiências. Nesse processo são considerados os aprendizados individuais, que ocorrem por meio das experiências e percepções dos indivíduos nos ambientes interno e externo, detectando e corrigindo erros; e o aprendizado coletivo, onde os grupos compartilham e integram essas experiências e conhecimentos sobre os ambientes que se situam, buscando ajustar os resultados às expectativas, isto é, a melhoria de desempenho.

\subsubsection{Abordagem de Inteligência Organizacional segundo Choo (1998)}

Choo (1998) argumenta que o aprendizado é a atividade fundamental para que seja alcançada a inteligência organizacional. Pois, o aprendizado da organização permeia o processo de inteligência e se intensifica à medida que são exigidos novos comportamentos ou ações por parte dela e de seus membros.

O processo de inteligência/aprendizagem organizacional de acordo com Choo (1998, p.15) é um ciclo contínuo de atividades que envolvem: o sensoriamento do ambiente, o desenvolvimento de percepções e, a construção de significados por meio da interpretação, utilizando a memória sobre as experiências passadas e agindo ou se comportando com base nas interpretações desenvolvidas.

O sensoriamento se refere à coleta de informações sobre o ambiente interno e externo. Como a organização não consegue atender a todos os eventos, ela captura esses eventos de exemplo para aprender, selecionando pontos prioritários e filtrando as mensagens de acordo com os seus interesses. Para Choo (1998) o ambiente é uma fonte de informações, assim, as 
Kelly Cristina Wilhelm de Toni, Lillian Maria Araújo de Rezende Alvares Educação Corporativa na perspectiva da Inteligência Organizacional

mudanças, eventos e tendências que nele ocorrem costumam criar e enviar sinais e mensagens, que devem ser detectadas e/ou monitoradas e recebidas pelas organizações para que possam usar tais informações para se adaptar às novas condições ambientais.

A memória se origina das experiências da organização como um todo na interação com o ambiente, e que é expressa formalmente por meio de documentos, manuais e procedimentos, e informalmente por meio de crenças ou valores, histórias e cultura organizacional. As experiências podem ser utilizadas para criar regras e estruturas que são usadas para combinar determinadas situações às respostas apropriadas, e referenciais que são usados para definir os problemas e as suas dimensões mais críticas. Neste ponto, é necessário identificar os fatos realmente importantes à empresa para a sua posterior armazenagem. Este processo pode evitar desperdícios de recursos e tempo, armazenando o que é ou será de fato relevante para a organização. Para tal, a utilização de tecnologia se torna indispensável para a armazenagem de grandes volumes de dados e informações.

A percepção se refere à identificação e representação de eventos ou cenas do ambiente externo usando o conhecimento que está disponível na memória. Isso inclui a classificação de objetos e eventos de acordo com categorias que são conhecidas ou que tenham sido encontradas antes. Essa percepção depende das normas, referenciais e regras que os membros da organização utilizam para visualizar as tendências e evoluções, e que é fortemente influenciada pela cultura organizacional. O processo apresenta um caráter social, fazendo com que nessa atividade de percepção o conhecimento que cada indivíduo possui seja imprescindível para compreender os ambientes interno e externo, bem como os conhecimentos gerados ao perceber esses ambientes.

A atividade de interpretação se situa no centro do ciclo de inteligência, é a criação de sentido sobre onde a organização estava no passado, onde está hoje, e onde quer estar no futuro. A descoberta de significado é um processo social, que exige pessoas socializando e trocando informações. O processo de interpretação pode ser compreendido pela tradução dos eventos externos, sendo criados modelos de compreensão desses eventos pelos indivíduos, 
oferecendo significados e formando conceitos capazes de auxiliar no entendimento do que ocorre fora da organização, mas que a afeta diretamente. Interpretação leva ao insight criativo pelo qual as consequências e oportunidades futuras são antecipadas e avaliadas de acordo com os objetivos e as estratégias.

Finalmente, o comportamento adaptativo se refere ao ciclo de aprendizado, onde à medida em que a organização toma decisões e realiza ações que geram efeitos e resultados, estes retroalimentam o ciclo modificando as estratégias de percepção (sensoriamento) e as estruturas e regras na memória. O aprendizado da organização está diretamente relacionado com as mudanças cognitivas e comportamentais que ocorrem nos indivíduos e grupos, referente aos processos organizacionais, como uma resposta à situações anteriores. Ao reiniciar o ciclo, o comportamento adaptativo possibilita à organização o monitoramento constante de seus ambientes, bem como de suas capacidades, dando sequência ao processo de adaptação e aprendizado.

\subsection{Educação Corporativa}

A educação corporativa se configura em uma dinâmica de aprendizagem contínua com foco no desenvolvimento das competências necessárias à organização e ao repasse dos conhecimentos.

Essa abordagem pressupõe que a empresa deve adotar o conceito de competência para articular e integrar as políticas e práticas de gestão de pessoas, alinhando as competências individuais às competências essenciais da organização.

Tem por objetivo educar e desenvolver funcionários de todos os níveis, inclusive os principais integrantes da cadeia de valor nas competências voltadas às estratégias dos negócios para que a empresa possa operar, com sucesso, em contextos de alto desempenho e competitividade (MEISTER, 1999, p. 29).

A organização que assume o compromisso com a educação atua essencialmente sobre três vertentes: (i) a aprendizagem formal, provendo ações de treinamento, desenvolvimento e educação alinhadas à sua estratégia e às necessidade de aprendizagem; (ii) a aprendizagem informal, estimulando, 
valorizando e apoiando o processo de autodesenvolvimento e a socialização de competências; e (iii) o ambiente de trabalho, criando um contexto profissional que seja facilitador e motivador da aprendizagem e da aplicação de competências no trabalho (BRANDÃO, 2011, p. 96).

A educação empresarial, representa um processo no qual os indivíduos passam a aprender continuamente uns com os outros, compartilhando inovações e melhores práticas para solucionar problemas relacionados ao ambiente de trabalho organizacional. A prioridade é entrar em contato com o conhecimento da organização como um todo, sempre tendo em vista os seus objetivos estratégicos.

Nessa circunstância, a criação e transferência de conhecimento são atividades centrais no processo. A educação nas corporações é um instrumento de mudança na cultura institucional, que apoia as atividades de gestão do conhecimento e incorpora o aprendizado da organização às práticas do negócio (TARAPANOFF, 2004, p. 91).

Destarte, a disseminação da cultura e a condução de mudanças em toda a organização é o eixo central da educação no mundo corporativo. Pois esta, sustenta e atende um modelo onde a aprendizagem contínua, o conhecimento e as competências são elementos essenciais que agregam valor aos negócios.

\subsubsection{Universidades corporativas}

Para manter uma força de trabalho com elevado nível de agregação de valor, muitas organizações têm investido no aprimoramento ou, até mesmo, na reinvenção da tradicional função de Treinamento e Desenvolvimento (T\&D), que passou a constituir importante instrumento de renovação dos conhecimentos e construção da competitividade empresarial fundamentada na aprendizagem.

Nesse sentido, as empresas criam seus próprios centros de capacitação com o objetivo de exercer um controle mais efetivo sobre o processo de aprendizagem. Vinculam suas ações e programas de educação às necessidades profissionais e organizacionais, consideradas críticas à realização das estratégias do negócio e à sustentação da vantagem competitiva. 
As universidades corporativas são complementares às universidades tradicionais, essas últimas fornecendo toda a formação conceitual e metodológica aos profissionais, enquanto a corporativa oportuniza a formação centrada no ambiente de negócios, desenvolvendo e aperfeiçoando nas competências essenciais ou críticas de cada organização.

Entretanto, na definição de Allen (2002, p. 9)a universidade corporativa é uma entidade educacional que se torna um instrumento estratégico, desenhada para assistir a organização (mantenedora) atingir a sua missão, na condução de atividades que criem a cultura do aprendizado individual e organizacional, e levem ao conhecimento e à sabedoria.

A atuação das universidades corporativas pode se estender um pouco além das atividades típicas de capacitação. Allen (2007, p. 6) citou uma lista de exemplos: planejamento de carreiras; orientação a novos empregados; planejamento de sucessão; preparação, execução e avaliação de programas de marketing interno e externo; avaliação de opções tecnológicas; gestão do conhecimento; desenvolvimento de programas de capacitação gerencial e executiva; desenvolvimento de e-learning; gerenciamento de relacionamentos; gestão dos parceiros; mentoring; coaching; mudança de cultura; mudança estratégica; e na prática do wisdom management, a qual dedica-se a colocar em ação os novos conhecimentos adquiridos.

Os principais modelos de educação corporativa encontrados na literatura pesquisada remetem aos trabalhos de Meister (1999), dentro de uma proposta de alinhamento estratégico voltada a princípios e objetivos, e de Prince e Beaver (2001), com uma proposta baseada na gestão do conhecimento voltada a processos. Ambas as propostas reconhecem a importância do aprendizado e do conhecimento como fatores determinantes das competências profissionais e organizacionais, e no alcance da vantagem competitiva sustentável.

\subsubsection{Abordagem de Universidade Corporativa segundo Meister (1999)}

Para desenvolver uma força de trabalho de altíssima qualidade,e oferecer uma aprendizagem ativa e contínua,Meister (1999) implementou um modelo conceitual de universidade corporativa baseado em princípios-chave dos programas de educação e desenvolvimento de diversas organizações. 
Esses elementos refletem a crença de que uma força de trabalho de uma empresa é seu principal recurso para a criação de uma diferenciação sustentável no mercado, onde ela desenvolve uma vantagem que não pode ser facilmente copiada e sempre pode ser renovada e aperfeiçoada.

Muito embora as universidades sejam diferentes em aspectos como formatos e tamanhos, estágios de desenvolvimento e maturidade, elas tendem a se organizar em torno de dez princípios e objetivos comuns, tornar-se uma instituição em que o aprendizado seja permanente. Segundo Meister (1999, p. 30-31) essas metas são:

1. Vincular as metas de educação e desenvolvimento às necessidades e aos resultados estratégicos da organização. Alinhar a aprendizagem com as competências básicas da organização, garante a trajetória correta da educação e do desenvolvimento, numa perspectiva informada e objetiva dos negócios.

2. Estimular a aptidão dos funcionários à aprendizagem, tentando incorporar o comprometimento e o acesso ao aprendizado permanente. $\mathrm{O}$ foco no funcionário é um processo estratégico contínuo e não um evento que ocorre apenas uma vez.

3. Desenvolver a Cidadania Corporativa (cultura, tradições, valores e visão da empresa), proporcionar uma Estrutura Contextual dos negócios para a empresa (produtos e serviços, clientes e fornecedores, concorrentes e as melhores práticas do setor), e criar Competências Básicas entre os funcionários. Essas competências combinam técnicas de como aprender, de comunicação e colaboração, resolução de problemas, conhecimento tecnológico, conhecimento de negócios globais, desenvolvimento de liderança e autogerenciamento da carreira. 4. Ampliar a atuação da universidade corporativa aos principais membros da cadeia de valor, isto é, funcionários, clientes e fornecedores, a comunidade e parceiros como instituições de ensino que fornecem pessoal recrutado.

5. Conduzir o treinamento com vários formatos de aprendizagem. Esses formatos de disseminação do conhecimento englobam o compartilhamento de experiências de sucesso, seja dentro da organização ou nas melhores práticas das empresas inovadoras. Entre as soluções estão as metodologias virtuais baseadas na internet $e$ intranet, via satélite, dentre outras.

6. Envolver líderes no papel de aluno e de professor.O comprometimento e envolvimento dos líderes no processo de aprendizagem é um fator muito importante para receber feedback e aprender com os funcionários em todos os níveis da organização. 
7. Estabelecer um modelo de obtenção de recursos via remuneração pelos serviços da universidade corporativa prestados a clientes, fornecedores e instituições de ensino.

8. Oportunizar aos funcionários da organização o conhecimento do universo empresarial globalizado. Capturar as melhores práticas (benchmarking) de várias partes do mundo e incorporá-las aos programas de treinamento e funções corporativas.

9. Demonstrar o valor da infraestrutura de aprendizagem da universidade corporativa. A importância de desenvolver métricas para avaliar a contribuição do investimento na educação dos funcionários está na realização ou cumprimento de uma estratégia empresarial.

10. Utilizar a universidade corporativa para obter vantagem competitiva, novos clientes e entrar em novos mercados. Isso acontece, se a universidade corporativa conseguiu realmente desenvolver uma força de trabalho altamente qualificada e tecnologicamente sofisticada.

\subsubsection{Abordagem de Universidade Corporativa segundo Prince e Beaver} (2001)

Para criar capacidade estratégica em gerir o conhecimento organizacional, Prince e Beaver (2001) implementaram um modelo de universidade corporativa baseado nas teorias da aprendizagem e gestão do conhecimento. Sob uma abordagem de ciclo integrado, o modelo proposto se compõe de quatro processos-chave: sistemas e processos de conhecimento, redes e parcerias, pessoas e processos, e processos de aprendizado.

Nenhum dos processos e sistemas é novo ou único, e as organizações podem operá-los sem o auxílio da universidade corporativa. No entanto, o que os autores propõem é que a universidade corporativa de alto nível, deve buscar coordenar, integrar e alinhar esses diversos processos a fim de maximizar o aprendizado do indivíduo e da organização. Cada um dos quatro processoschave é discutido, por sua vez, segundo Prince e Beaver (2001, p. 22-23).

Sistemas e processos de conhecimento se referem à capacidade da organização em capturar e armazenar os conhecimentos decorrentes de suas experiências sobre o ambiente interno e externo, por meio de tecnologias como bases de dados, sistemas especialistas e softwares para tomada de decisão. No entanto, esta tecnologia deve estar acessível para que as pessoas possam recuperar a informação para usá-la e agir com base nesses sistemas. Assim, a implementação desse processo pode ocorrer por intranets, internet e bases de 
outros sistemas. A ideia é garantir que a aprendizagem individual seja coletada e feita disponível como um recurso para o benefício de toda a organização.

Redes e parcerias se referem não apenas às comunidades internas e externas conectadas à organização, mas aos processos que promovem e controlam as formas como os indivíduos interagem e trocam informações e experiências com as comunidades. Isto pode ocorrer por meio eletrônico em rede, mas também por meio de uma rede de relacionamentos pessoais e contatos de negócios. Nesse contexto, procura facilitar o desenvolvimento de parcerias com instituições de ensino para oferecer intervenções de aprendizagem dentro da organização. As redes de relacionamento com o público interno e externo, bem como parcerias, visam privilegiar a construção social do conhecimento e a troca de experiências, estabelecendo conexões e intensificando a comunicação e a interação.

Pessoas e processos se referem aos sistemas e procedimentos que constroem e reforçam o significado compartilhado (sentidos comuns de visão, objetivos e valores) e facilitam a aprendizagem na organização. Isto não só se relaciona com os níveis de habilidade e capacidades dos funcionários para utilizar as tecnologias, mas também as maneiras pelas quais a organização pode construir mecanismos adequados para criar uma cultura aceita e produtiva. Esses processos são dirigidos principalmente por meio de práticas modernas de Desenvolvimento de Recursos Humanos para garantir que além do fornecimento de educação e treinamento, todas as políticas de obtenção de recursos humanos da organização estejam estrategicamente alinhados para apoiar a aprendizagem e a partilha de conhecimentos.

Processos de aprendizagem sereferem ao desenvolvimento de uma cultura apoiada e baseada em aprendizado. Embora sejam os programas de educação e treinamento associados com as ações da universidade corporativa, o objetivo é implementar os aspectos potenciadores e facilitadores da aprendizagem individual e organizacional, e erradicar os inibidores do aprender. Na cultura de aprendizagem, a criação de conhecimento e o aprendizado ocorrem continuamente. E na organização que apoia essa cultura, o aprendizado é incorporado ao trabalho implementando o que foi aprendido a partir das oportunidades de educação, a experimentação e o diálogo são 
Kelly Cristina Wilhelm de Toni, Lillian Maria Araújo de Rezende Alvares Educação Corporativa na perspectiva da Inteligência Organizacional

incentivados, as experiências de aprendizado são compartilhadas e ocorre a busca constante por melhoria.

\section{RESULTADOS}

\subsection{Abordagem de relação entre os processos da Inteligência Organizacional e Educação Corporativa}

Para fins de menção, este estudo se refere à inteligência organizacional como a capacidade da organização em mobilizar recursos e habilidades para transformar informação em conhecimento, e utilizar estrategicamente esse conhecimento para agir de modo racional, visando resolver problemas e auxiliar a tomada de decisão no ambiente de trabalho. Permeia em uma cultura organizacional que apoia a gestão do conhecimento e o aprendizado individual e coletivo, buscando agregar valor aos negócios, e por sua vez, melhorar o desempenho e sustentar vantagem competitiva com foco na missão da organização.

Refere-se à educação corporativa como um recursocatalisador da criação e transferência dos conhecimentosvoltado ao aprendizado individual e organizacional e a incorporação deste às práticas de negócios, buscando solucionar problemas reais e melhorar o desempenho no trabalho. Conduz mudanças na cultura institucional, apoiando as atividades de gestão do conhecimento para atender um modelo de aprendizagem contínua com o objetivo de desenvolver as competências que agregam valor estratégico e diferencial competitivo à organização, consoantes com a sua visão e missão.

Para identificar e explicitar as conexões entre a inteligência organizacional e a educação corporativa, utilizou-se como referencial teórico a convergência entre as abordagens de processo da inteligência organizacional propostas por Matsuda (1993) e Choo (1998), e a abordagem de processo da educação corporativa proposta por Prince e Beaver (2001). Meister (1999) define a educação em corporações como um processo, porém, implementou um modelo conceitual baseado sobre um conjunto de princípios e objetivos em educação e desenvolvimento organizacional, e sob esse aspecto, portanto, não sendo utilizada como referência para definição de uma abordagem de relação, mas como referência às atividades. 
A partir das definições apresentadas para cada componente-chave que compõe a abordagem de processo da educação corporativa (PRINCE; BEAVER, 2001), uma relação foi efetuada com os componentes da abordagem de processo da inteligência organizacional (convergência entre Matsuda, 1993 e Choo, 1998), dentro de uma visão paralela estruturada no quadro 2, conforme segue.

Quadro 2 - Relação entre as abordagens de processo da Inteligência Organizacional e Educação Corporativa

\begin{tabular}{|c|c|}
\hline $\begin{array}{l}\text { Educação Corporativa } \\
\text { (PRINCE; BEAVER, 2001) }\end{array}$ & $\begin{array}{c}\text { Inteligência Organizacional } \\
\text { (Convergência entre Matsuda, } 1993 \text { e } \\
\text { Choo, 1998) }\end{array}$ \\
\hline $\begin{array}{l}\frac{\text { Sistemas e Processos de }}{\text { Conhecimento }} \\
\text { Captura/Aquisição de conhecimentos } \\
\text { resultantes das experiências. }\end{array}$ & 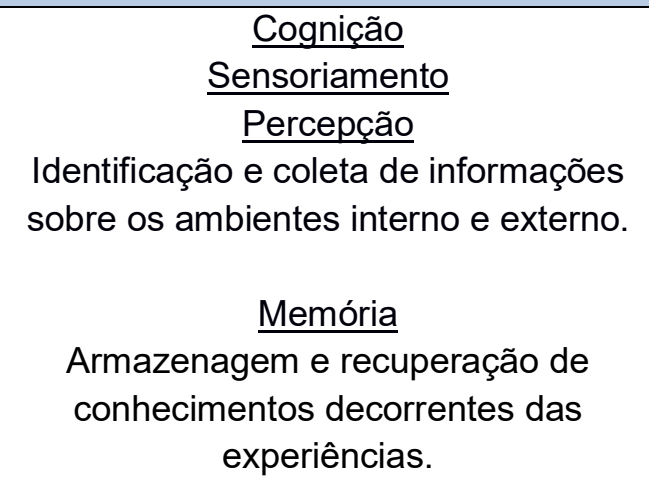 \\
\hline $\begin{array}{c}\text { Interação e troca de conhecimentos e } \\
\text { experiências. }\end{array}$ & $\begin{array}{l}\frac{\text { Comunicação }}{\text { Interpretação }} \\
\text { Construção de significados por meio da } \\
\text { troca de informações e conhecimentos. }\end{array}$ \\
\hline $\begin{array}{l}\text { Pessoas e Processos } \\
\text { Construção de visão/significado } \\
\text { compartilhado. }\end{array}$ & $\begin{array}{c}\frac{\text { Raciocínio }}{\text { Interpretação }} \\
\text { Construção e uso de significados ou } \\
\text { conhecimentos na resolução de } \\
\text { problemas e tomada de decisões. }\end{array}$ \\
\hline $\begin{array}{c}\text { Processos de Aprendizagem } \\
\text { Cultura de aprendizagem individual e } \\
\text { organizacional. }\end{array}$ & $\begin{array}{c}\frac{\text { Aprendizado }}{\text { Comportamento Adaptativo }} \\
\text { Capacidade de uma organização } \\
\text { modificar o seu modo de pensar e agir. }\end{array}$ \\
\hline
\end{tabular}

Fonte: Das autoras com base em Prince e Beaver (2001), Matsuda (1993) e Choo (1998).

Entre os processos de educação corporativa e inteligência organizacional, respectivamente, o componente sistemas e processos de conhecimento se relaciona aos componentes convergentes cognição, sensoriamento, percepção e memória, por meio da captura de conhecimentos, experiências e melhores práticas. Este compreende o processo de aquisição 
de conhecimentos tanto em fonte interna como externa, qual procura coletar, armazenar e organizar o conhecimento individual e organizacional por meio de tecnologias para posterior recuperação e uso, preservando-o como memória organizacional, com a finalidade de aprendizado e auxílio à tomada de decisão.

O componente redes e parcerias se relaciona aos componentes convergentes comunicação e interpretação por meio da interação e troca de conhecimentos entre o ambiente interno e externo da organização. O processo compreende as formas de interação entre indivíduos e grupos que estão interna e externamente conectados à organização com o objetivo de compartilhar e trocar conhecimentos, experiências e melhores práticas.

Já o componente pessoas e processos está relacionado aos componentes convergentes raciocínio e interpretação a partir da construção de uma visão ou signficado compartilhado na organização. Tal processo se refere aos mecanismos relacionados na construção de um entendimento ou finalidade comum de acordo com os objetivos da organização, procurando alinhar estrategicamente pessoas e processos para apoiar a aprendizagem coletiva e a partilha/troca de conhecimentos.

Por fim, o componente processos de aprendizagem se relaciona aos componentes convergentes aprendizado e comportamento adaptativo por meio de uma cultura de aprendizado na organização. Este processo compreende ações e atividades que apoiam e facilitam a aprendizagem individual e organizacional, onde a criação do conhecimento e a busca por melhorias e resultados acontecem de maneira contínua.

De forma teórica, a relação apresentada por meio dos componenteschave permitiu identificar um conjunto que é composto por elementos comuns entre as abordagens discutidas. Esses elementos podem ser representados a

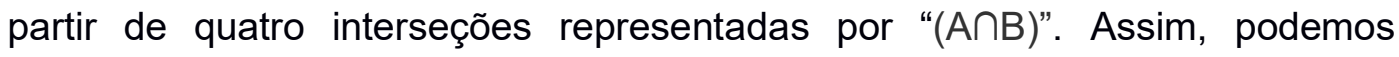
considerar que:

Conjunto $\mathrm{A}$ = Abordagem da Educação Corporativa (PRINCE; BEAVER, 2001).

Conjunto $B=$ Abordagem da Inteligência Organizacional (convergência entre Matsuda, 1993 e Choo, 1998). 
Kelly Cristina Wilhelm de Toni, Lillian Maria Araújo de Rezende Alvares Educação Corporativa na perspectiva da Inteligência Organizacional

Interseção 1: Captura $(A \cap B)$

Conjunto $A \cap$ Conjunto $B$

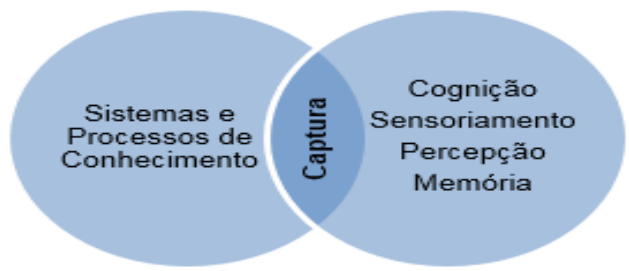

Interseção 2: Compartilhamento $(A \cap B$

Conjunto A $\cap$ Conjunto B

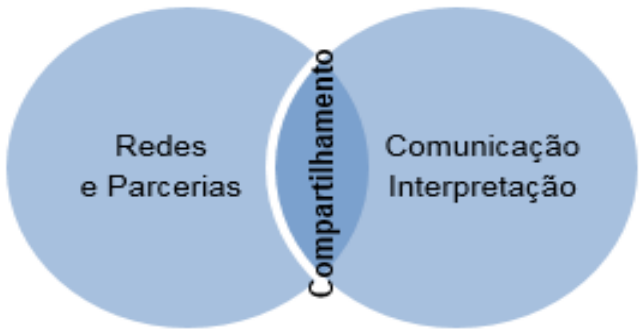

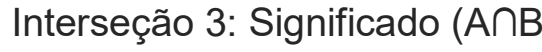

Conjunto A $\cap$ Conjunto B

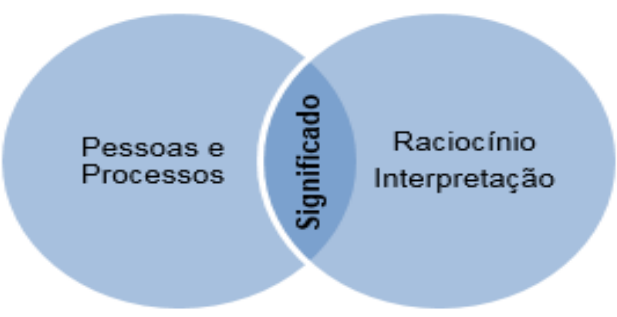

I

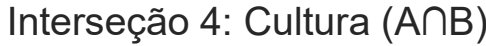

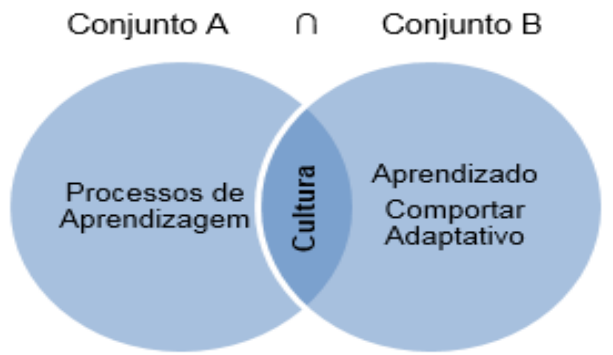

Os elementos evidenciados a partir das interseções entre o conjunto A e o conjunto B correspondem ao seguinte: a captura/aquisição de conhecimentos e experiências (Captura), a interação e troca de conhecimentos e experiências 
(Compartilhamento), a visão ou significado compartilhado (Significado) e, a cultura de aprendizado individual e organizacional (Cultura).

Esses elementos agora permitem a construção de uma estrutura aderente entre as abordagens de processo da educação corporativa e da inteligência organizacional.

\subsection{Aderência entre os processos da Inteligência Organizacional e Educação Corporativa}

Conforme a descrição feita por meio do conjunto de interseções, procurou-se classificar os elementos então identificados por meio da abordagem de processo da educação corporativa com a convergência das abordagens de processo da inteligência organizacional de acordo com os componentes: cognição, sensoriamento, percepção, memória, comunicação, raciocínio, interpretação, aprendizado e comportamento adaptativo.

Portanto, a partir da busca dos elementos de relação do processo de educação corporativa, o quadro 3 apresenta de forma consolidada estes elementos aderentes aos componentes do processo de inteligência organizacional, permitindo ter uma visão horizontal e vertical entre as abordagens.

Quadro 3 - Elementos de aderência entre os processos de Inteligência Organizacional e Educação Corporativa.

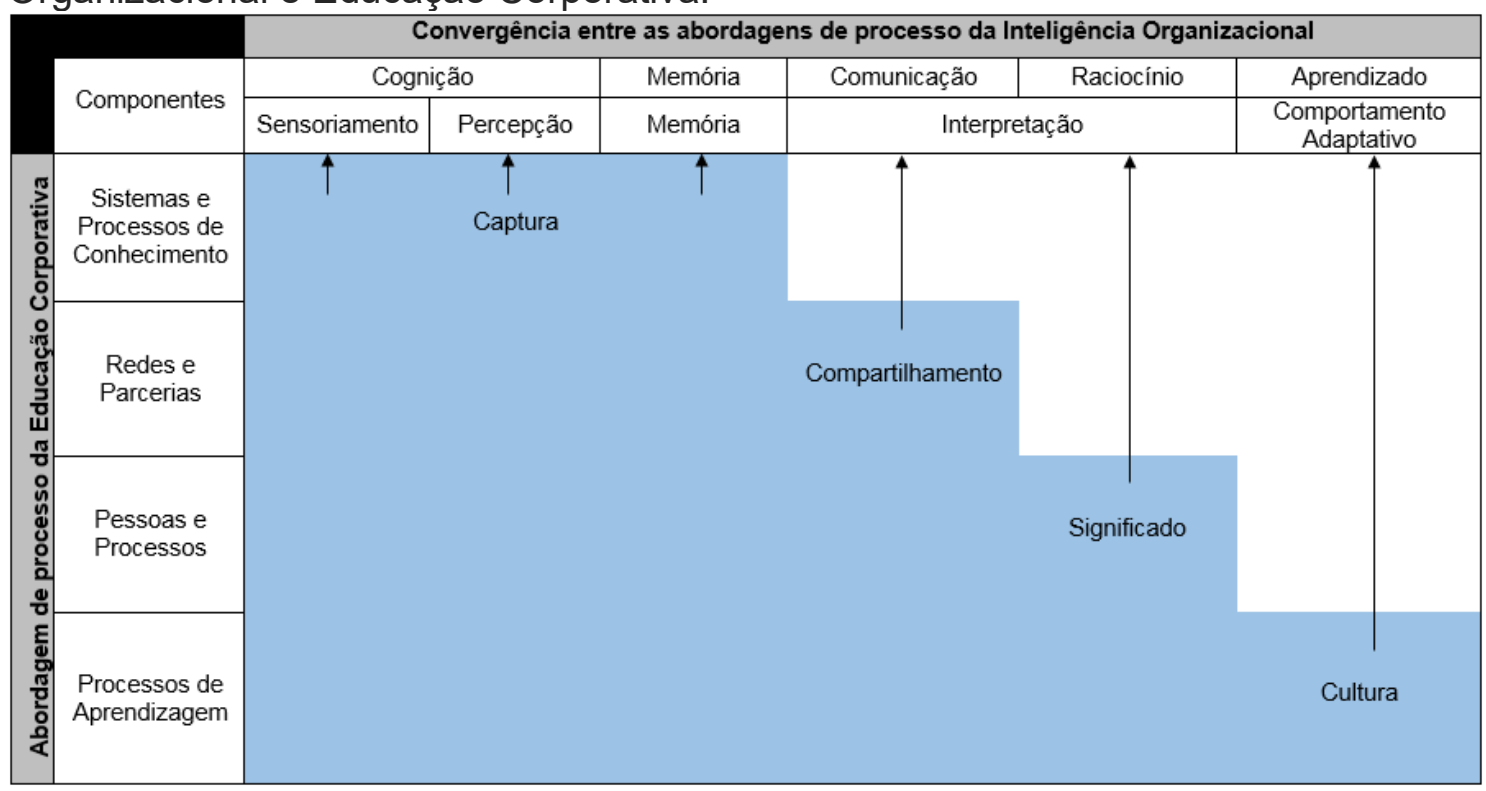

Fonte: Das autoras (2015).

Inf. Inf., Londrina, v. 21, n. 3, p. 228 - 257, set./dez., 2016. 


\section{CONCLUSÃO}

O contexto da inteligência organizacional remete a uma necessidade de atenção tanto no nível individual quanto nos níveis coletivos de ações organizacionais. Como uma destas ações, se destaca as iniciativas contínuas de qualificação e capacitação dos recursos humanos, isto é, a educação corporativa.

A valer, a meta da educação corporativa não é somente desenvolver as competências empresariais e humanas essenciais às estratégias do negócio, mas inclusive desenvolver e aperfeiçoar a inteligência de indivíduos e organização.

Por meio deste estudo, se pôde conhecer a contribuição e o potencial da educação corporativa sob a perspectiva da inteligência organizacional, a partir do objetivo geral, ou seja, da proposta de metodologia para analisar a relação entre as duas abordagens.

Tal proposta, implicou identificar os principais modelos de processo, e os respectivos componentes-chave da inteligência organizacional e da educação corporativa a serem utilizados como referência teórica na definição de um instrumento para sua análise. O esforço principal consistiu na realização das convergências entre os modelos, por meio dos seus componentes-chave, para tornar explícita as suas conexões e efetuar uma relação com cada unidade do processo.

Esse movimento de relação permitiu identificar um conjunto de elementos comuns entre as abordagens discutidas. Esses elementos foram representados a partir de quatro interseções que correspondem: a captura/aquisição de conhecimentos e experiências (Captura), a interação e troca de conhecimentos e experiências (Compartilhamento), a visão ou significado compartilhado (Significado) e, a cultura de aprendizado individual e organizacional (Cultura).

Os elementos evidenciados pela interseção possibilitaram a construção de uma estrutura de aderência, classificando-os, entre os modelos de processo convergentes da inteligência organizacional e da educação corporativa, conforme o item 4.2. Doravante, infere-se que existe uma legítima e verdadeira conexão entre as abordagens do estudo. 
Como consequência direta da proposta de aderência, concluiu-se que essa estrutura pode ser percebida como um instrumento para explicar e até avaliar o processo de educação nas corporações pela perspectiva da inteligência organizacional.

Portanto, e finalizando, a inteligência organizacional e a educação corporativa tomam como atividade motor a captura e compartilhamento de conhecimentos e melhores práticas nos níveis de indivíduo, grupo e organização para aprender continuamente de acordo com um significado e assim, escolher e empreender cursos de ação apropriados com base no conhecimento criado coletivamente.

Inseridas num cenário estratégico, ambas abordagens buscam adaptar a organização ao ambiente de negócios em constante mudança, ampliando e atualizando de forma permanente seus conhecimentos e competências, possibilitando alcançar a realização dos seus objetivos e missão, e conquistar vantagem competitiva.

\section{REFERÊNCIAS}

ALLEN, M. (Org). The Corporate university handbook: designing, managing and growing a successful program. New York: Amacom, 2002. p.43-66.

(Org.) The next generation of corporate universities: innovative approaches for developing people and expanding organizational capabilities. São Francisco: John Wiley and Sons, 2007. 410 p.

ANTONELLO, C. S. A metamorfose da aprendizagem organizacional: uma revisão crítica. In: RUAS, R. L., ANTONELLO, C. S.; BOFF, L. H. (Org.) Os novos horizontes da gestão: aprendizagem organizacional e competências. Porto Alegre: Bookman. 2005. p.12-33.

BRANDÃO, H. P. Aprendizagem e desenvolvimento de competências: conceitos, pressupostos e práticas. In: TARAPANOFF, Kira. (Org).

Aprendizado Organizacional: contextos e propostas, vol. 2. Curitiba: Ibpex, 2011. p.95-96.

CARBONE, P. P. et al. Gestão por competências e gestão do conhecimento. Rio de Janeiro: FGV, 2005. 
CHOO, C. W. A organização do conhecimento: como as organizações usam a informação para criar significado, construir conhecimento e tomar decisões. São Paulo: Senac, 2003.

Information management for the intelligent organization: the art of scanning the environment. $2^{\mathrm{a}}$ ed. Medford, NJ: Information Today, Inc., 1998.

DUMONT, D. M. et al. Inteligência pública na era do conhecimento. Rio de Janeiro: Revan, 2006.

EBOLI, M. Educação Corporativa no Brasil: Mitos e Verdades. São Paulo: Gente, 2004.

. (Coord.). Universidades corporativas: educação para as empresas do século XXI. São Paulo: USP, 1999. (Coletânea Universidades Corporativas).

. Dez anos de educação corporativa no Brasil. In: Simpósio Internacional de educação corporativa no Brasil. FIA, FEA-USP. São Paulo, novembro, 2009.

FUNDAÇÃO INSTITUTO DE ADMINISTRAÇÃO (FIA). Relatório da Pesquisa Nacional de Educação Corporativa no Brasil. São Paulo: FIA, 2012.

FLEURY, M.T.L.; FLEURY, A. Estratégias empresariais e formação de competências: um quebra-cabeça caleidoscópio da indústria brasileira. $2^{\mathrm{a}} \mathrm{ed}$. São Paulo: Atlas, 2004.

GARVIN, D.A. Construção da organização que aprende. In: conhecimento. Harvard Business Review, Rio de Janeiro, p. 50-81, 2001.

MATSUDA, T. Organizational intelligence: theory of collectively intelligent behaviors and engineering of effective information systems in the complex organizations. In Sanno College, Isehara, Japão, 1993.

MEISTER, J. Educação corporativa: a gestão do capital intelectual através das universidades corporativas. São Paulo: Pearson Makron Books, 1999. 296 p.

MORESI, Eduardo. Inteligência Organizacional: um referencial integrado. Revista Ciência da Informação, Brasília, v. 30, n. 2, p. 35-46, maio/ago. 2001.

NONAKA, I; TAKEUCHI, H. Criação de conhecimento na empresa:como as empresas japonesas geram a dinâmica da inovação. Rio de Janeiro: Campus, 1997. 
PESQUISA NACIONAL SOBRE PRÁTICAS E RESULTADOS DA EDUCAÇÃO CORPORATIVA NO BRASIL. FEA-USP Press Releases, novembro de 2009.

PRINCE, C.; BEAVER, G. The rise and rise for corporate universities: the emerging corporate learning agenda. International Journal of Management Education, vol.1, n.2, p.17-26, 2001

SENGE, P. M. A quinta disciplina: arte e prática da organização que aprende. $16^{\mathrm{a}}$ ed. São Paulo: Editora Best Seller, 2004.

STOLLENWERK, M.F.L. Gestão do conhecimento: conceitos e modelos. In: TARAPANOFF, Kira. (Org.) Inteligência organizacional e competitiva, Brasília: UnB, 2001. p.143-163.

SVEIBY, K. E. What is knowledge management? 2001a. Disponível em http://www.sveiby.com/articles/KnowledgeManagement.html.

TARAPANOFF, K. (Org.). Inteligência organizacional e competitiva. Brasília: UnB, 2001. 343p.

Panorama da Educação Corporativa no contexto internacional. In: Educação Corporativa: Contribuição para a competitividade. (Org.) Secretaria de Tecnologia Industrial. Brasília: Petróleo Brasileiro e CNI, 2004, p.12-84.

TERRA, J.C.C. Gestão do conhecimento: o grande desafio empresarial. São Paulo: Negócio Editora, 2000. 313p.

WOIDA, L. M.; VALENTIM, M.L. P. Cultura organizacional no processo de inteligência competitiva. DataGramaZero, Rio de Janeiro, v. 5, n. 4, ago. 2004.

ZARIFIAN, P. O modelo da competência: trajetórias históricas, desafios atuais e propostas. São Paulo: Senac, 2003.

Title

Corporate Education in perspective of Organizational Intelligence.

Abstract:

Introduction: To meet the challenges of competitiveness and achieve the conditions for generation of innovation is necessary to ensure that the workforce remains highly qualified. In this context, corporate education is an alternative.

Objective: To develop a method to analyze the relationship between process approaches Organizational Intelligence and Corporate Education.

Methodology: Theoretical construction performed based on literature review.Construction a methodological approach linked to the problem of this research. 
Results: Identification of a set of common elements between the approaches: the"Capture" and "Sharing" of knowledge and experience, the "meaning" shared and "Culture" of individual and organizational learning.

Conclusions: There is a real connection between the approaches of the study. The proposed method can be seen as a tool to explain and evaluate the process of education in the enterprise from the perspective of organizational intelligence.

Keywords: Corporate Education. Organizational Intelligence. Corporate Education and Organizational Intelligence.

\section{Titulo}

Educación Corporativa en la Perspectiva de la Inteligencia Organizacional.

\section{Resumen:}

Introducción: Para hacer frente a los retos de la competitividad y lograr las condiciones para generar innovación es necesario asegurarse de que la mano de obra sigue siendo altamente cualificado. En este contexto, la educación corporativa es una alternativa.

Objetivo: Desarrollar un método para analizar la relación entre el proceso se acerca Inteligencia Organizacional y Educación Corporativa.

Metodología: Construcción teórica realizada en base a revisión de la literatura. Y la construcción de un enfoque metodológico relacionado con el problema de esta investigación.

Resultados: La identificación de un conjunto de elementos comunes entre los enfoques: la "captura" y de "compartir" el conocimiento y la experiencia, el "significado" compartida y "Cultura" del aprendizaje individual y organizacional.

Conclusiones: Existe una conexión verdadera entre los enfoques del estudio. El método propuesto puede ser percibido como una herramienta para explicar y evaluar el proceso de la educación en la empresa desde la perspectiva de la inteligencia organizacional.

Palabras clave: Educación Corporativa. Inteligencia organizacional. La educación empresarial y la inteligencia organizacional.

Recebido em: 10.04.2016

Aceito em: 18.11.2016 